\title{
Relations between occupation, smoking, lung function, and incidence and mortality of chronic non-specific lung disease: the Zutphen Study
}

\author{
Dick Heederik, Hans Kromhout, Daan Kromhout, Jan Burema, Klaas Biersteker
}

\begin{abstract}
Information gathered in the "Zutphen study", the Dutch contribution to the Seven Countries Study was used for the present study. Follow up data from 1965 to 1 July 1985 were used. During this follow up, the morbidity state of the participants was verified at regular intervals. In 1965 lung function was measured by spirometry and the vital capacity (VC) and forced expiratory volume in one second $\left(F_{E V}\right)$ were available. A complete set of data was available for 668 men. The occurrence of chronic non-specific lung disease (CNSLD) at a specific time was coded by one physician, using strict criteria. Information about the cause of death was obtained and coded by one physician in 1985. Occupation was coded and a distinction between blue and white collar workers was made. For the analysis of the relation between age, lung function, smoking habits, and occupational state with CNSLD incidence and mortality, proportional hazard models were used. Blue collar workers had a significantly raised risk for incidence of CNSLD only. The hazard ratio for blue $v$ white collar workers with CNSLD mortality was 1.4 but not statistically significant. It was concluded that occupation is clearly related to incidence of CNSLD. There were indications that occupation is related to mortality from CNSLD. A reduced FEV was a strong predictor of both CNSLD incidence and mortality. It is noteworthy that small differences in age and height
\end{abstract}

Department of Epidemiology and Public Health, Wageningen University, PO Box 238, 6700 AE Wageningen, The Netherlands

D Heederik, J Burema, K Biersteker

Department of Air Pollution, Wageningen University, The Netherlands

H Kromhout

Department of Epidemiology, National Institute of Public Health and Environmental Protection, Bilthoven, The Netherlands

D Kromhout standardised lung function were significantly related to incidence of CNSLD, mortality from CNSLD, and total mortality. Although these differences in lung function have no direct clinical importance for the individual subject, they indicate a raised morbidity and mortality risk for the population.

The relation between total mortality, cause specific mortality, and explanatory variables such as lung function, respiratory symptoms, and smoking habits have been studied during the last decade in large community based studies and occupational group studies. ${ }^{1-12}$ For most, the aims were to establish the predictive value of lung function measurements or respiratory symptoms for various outcomes such as total mortality or cause specific mortality from, for example, respiratory diseases or ischaemic heart disease. Few of those studies focused on the role of occupational exposures on total mortality or cause specific mortality, and results have been conflicting. ${ }^{13-16}$ Another limitation of these studies is that they only focus on mortality data. It is generally known that the mortality from chronic non-specific lung disease (CNSLD) is low whereas morbidity is relatively high. An analysis based on incidence data could therefore give new insights into the relation between lung function at the start of follow up, smoking, and occupation.

In the present study we therefore analysed the effects of occupational state, lung function, and smoking habits on incidence of CNSLD, mortality from CNSLD, and total mortality in the Zutphen Study, to provide further evidence for the relation between these variables.

\section{Material and methods}

SUBJECTS

Since 1960, a longitudinal investigation of risk factors for chronic diseases has been carried out among middle aged men from the town of Zutphen in The Netherlands. The Zutphen Study is the Dutch contribution to the Seven Countries Study. ${ }^{17}$ Zutphen is an old industrial town situated in the east of the Netherlands. In 1960 it had 25000 inhabi- 
tants. A random sample of 1088 men was selected; all were born between 1900 and 1919 and had lived in Zutphen for at least five years. Of the 1088 invited men, 878 aged 40 to 59 took part in the medical examination. Risk factors such as smoking habits were assessed according to the Seven Countries Study protocol. The information available on current and past cigarette consumption was used to calculate pack-years, as the product of the number of years smoked and the number of packs of cigarettes smoked per day. A pack was assumed to contain 25 cigarettes. For the analysis presented here, follow up data since 1965 were used, because in 1965 lung function was measured in the men still participating in the study.

\section{QUESTIONNAIRE}

During the 1960 and 1965 surveys, information about occupation was asked for in an open question as part of a dietary survey. The occupation was coded in 1989 according to the British Central Statistical Offices 1968 classification of industries ${ }^{18}$ and the Registrar General's 1966 classification of occupations. ${ }^{19}$ If the name of a specific factory or company was mentioned, further information was gathered from occupational health services in the region, the Chamber of Commerce of Zutphen and Arnhem, and other local authorities to confirm the classification of this industry. By this procedure more than $90 \%$ of the factories and companies mentioned could be traced. Coding was done by two of us (D Heederik, $\mathrm{H}$ Kromhout) independently. Codes were only accepted if there was agreement, or if agreement could be reached after comparison of the codes, followed by recoding. Detailed information about the jobs performed and types of industries has already been published. ${ }^{20}$ For those 26 persons who retired between 1960 and 1965 the job in 1960 was used for the analysis.

\section{MEDICAL EXAMINATION}

Between 1960 and 1973 all subjects were medically examined annually. Subsequently, they were reexamined in the next survey in 1977 and 1978. The last medical examination was carried out in 1985. In 1980 and 1982 they were given a questionnaire about their health. Information about any mentioned morbidity was verified by contacting the general practitioner of the participant. The vital status of the 878 men were verified after 25 years of follow up. Each person had a complete follow up until 1 July 1985 . During the years of the follow up 430 men died. Information about the cause of death was obtained from the death certificate, and from the hospital or the general practitioner. The information on the causes of death on the death certificate was compared with the morbidity history of the participant. When no differences were found the causes of death on the death certificate were used for further analysis. When there was no agreement the case was discussed by the survey physician and the physician of the Central Bureau of Statistics (CBS) and a final decision was reached. The CBS is responsible for coding of death certificates in The Netherlands. The causes of death were coded according to the eighth revision of the International Classification of Diseases (ICD-8), 1969). The cause of death was considered to be due to CNSLD if ICD codes 490.0 to $496 \cdot 0$ were mentioned on the death certificate. For the analysis of CNSLD mortality data, we considered not only the primary cause of death, but also the other causes of death registered on the death certificate (secondary and tertiary causes). One physician, using strict criteria, coded all the information about morbidity during the 25 years of follow up. The diagnosis of CNSLD was based on the following criteria: episodes of respiratory symptoms such as regular cough and phlegm for longer than three months and episodes of wheezing and shortness of breath reported to the survey physician or: diagnosis of CNSLD, including asthma, chronic bronchitis, or emphysema by a clinical specialist.

In those who attended the 1965 survey, lung function was measured by spirometry. Vital capacity (VC) and forced expiratory volume in one second $\left(F_{E V}\right)$ were measured with a Godart Pulmotest by one technician. The procedures have been described in detail..$^{21}$ Measured values were corrected to body temperature and pressure saturated (BTPS). The VC was measured by three maximal inhalations. The highest VC was used for calculations presented here. The FEV 1 was established by three attempts. The two highest $\mathrm{FEV}_{1}$ values should not differ by more than $50 \mathrm{ml}$. If the difference was larger than $50 \mathrm{ml}$ one extra $F E V_{1}$ had to be produced. The mean of the two closest values was used for further calculations. The selected $\mathrm{FEV}_{1}$ divided by the VC was calculated, $\left(\mathrm{FEV}_{1} / \mathrm{VC} \%\right)$ and used for further analysis.

\section{STATISTICAL ANALYSIS}

All analyses were performed using Statistical Analysis System software (SAS) packages on a VAX computer system. The relation between occupation and lung function was studied after allowing for smoking (pack-years and a dummy variable for cigar and pipe) and standing height and age in a multivariate regression analysis. Lung function of "blue collar workers" (occupational code 1-138) was compared with lung function of "white collar workers" (occupational code 139-210).

The 20 year survival of the population was initially studied by univariate survival (Kaplan-Meier) curves produced with Proc PHGLM. For the analysis of mortality from CNSLD, deaths from 
Table 1 Characteristics of 668 men of the Zutphen population in 1965. Break down to occupational codes according to classification of occupations ${ }^{\star}$

\begin{tabular}{|c|c|c|}
\hline & $\operatorname{Mean}(S D)$ & No (\%) \\
\hline $\begin{array}{l}\text { Age (y) } \\
\text { Standing height }(\mathrm{cm}) \\
\text { VC(1) } \\
\text { FEV } 1 \text { (l) } \\
\text { Pack-years cigarettes } \\
\text { (pack/day.years) } \\
\text { Number of years smoked (y) }\end{array}$ & $\begin{array}{c}54.8(12 \cdot 6) \\
173.9(6.5) \\
4.25(0 \cdot 77) \\
2.96(0 \cdot 70) \\
\\
16.5(12 \cdot 2) \\
31.4(12 \cdot 6)\end{array}$ & \\
\hline $\begin{array}{l}\text { Smoking categories: } \\
\text { Non-cigarette smokers } \\
\text { Ex-cigarette smokers }\end{array}$ & & $\begin{array}{rr}51(7 \cdot 6) \\
214(32 \cdot 0)\end{array}$ \\
\hline $\begin{array}{l}\text { Current cigarette smoker: } \\
<5 \text { cigarettes per day } \\
5-9 \text { cigarettes per day } \\
10-19 \text { cigarettes per day } \\
20-29 \text { cigarettes per day } \\
\geqslant 30 \text { cigarettes per day } \\
\text { Current cigar or pipe smokers }(0 / 1)\end{array}$ & & $\begin{array}{r}49(7 \cdot 3) \\
76(11 \cdot 4) \\
173(25 \cdot 9) \\
92(13 \cdot 8) \\
13(2 \cdot 0) \\
379(56 \cdot 7)\end{array}$ \\
\hline $\begin{array}{l}\text { Occupation: } \\
\text { White collar workers }(139-210)^{\star} \\
\text { Blue collar workers }(1-138)^{\star}\end{array}$ & & $\begin{array}{l}322(48 \cdot 2) \\
346(51 \cdot 8)\end{array}$ \\
\hline
\end{tabular}

*General Register Office. ${ }^{19}$

other causes were treated as events that made a further follow up impossible ("censoring events"). For this analysis smoking habits were categorised in three subgroups of equal size for duration of smoking habits up to 1965 (category 1: mean 16.9 (standard deviation (SD) $11 \cdot 7)(n=210)$; category 2 : mean 33.8 (SD 1.7) $(n=220)$; category 3: mean 42.1 (SD $3.8)(n=238)$ years). Pack-years smoked up to 1965 were also stratified into three equally sized categories (category 1 : mean $5 \cdot 2(\mathrm{SD} 4 \cdot 1)(\mathrm{n}=269)$; category 2 : mean 8.4 (SD 4.0) $(n=242)$; category 3: mean 33.1 (SD 9.1) $(\mathbf{n}=157)$ pack years). For each subject a reference value of his lung function was calculated from a regression model with age and standing height as predictors. Departures of observed values from the predicted values were calculated as residuals (for example, lung function mesared - lung function $n_{\text {predicted }}$ ) and used for further analysis. Survival curves were produced for lung function by comparing the group with subjects who had lung function residuals greater than zero (above average), those with a negative residual between zero and one SD of the distribution of the residuals, those with a negative residual between one and two SDs, and those with a negative residual larger than two SDs of the distribution of the residuals. For the $\mathrm{FEV}_{1}, \mathrm{VC}$, and $\mathrm{FEV}_{1} / \mathrm{VC} \%$ the cut off points were 0,0 , and $0,-620 \mathrm{ml},-640 \mathrm{ml}$, and $-10 \%$, and $-1240 \mathrm{ml},-1280 \mathrm{ml}$, and $-20 \%$ respectively. To analyse the relation between survival and several independent variables simultaneously a proportional hazard analysis was conducted by using the PHGLM procedure in SAS. ${ }^{22}$ This model postulates that the ratios for any risk of death are constant over time. Assumptions of the proportional hazards model were checked by standard procedures such as visual inspection of survival and $\log \log$ curves for various combinations of independent variables. If any variable violated the proportional hazard assumption, a stratified analysis was carried out within Proc PHGLM. In such a stratified analysis the log likelihood function is calculated separately for each group, and component likelihoods are summed over the groups to give an overall likelihood that is maximised for parameter estimation. For this specific situation, the Proc PHGLM obtains a generalised form of Mantel-Haenszel test statistics. The ratio of a regression coefficient divided by its standard error was used for testing whether the coefficient differed significantly from zero. Hazard ratios (or risk ratios) were calculated from the regression coefficients by taking the antilog of the regression coefficient. Only two tailed probabilities were used to test statistical significance.

\section{Results}

Table 1 gives the characteristics of the population of the Zutphen study in 1965. Of the 878 men who participated in the physical examination in 1960, 40 had died before 1 January 1965, for 159 no lung function data were available, and for 11 the information on their occupation was insufficient to code. Therefore a group of 668 remained for further analyses. Persons who developed CNSLD before 1965 were excluded from the analysis of incidence of

Table 2 Regression coefficients for age, standing height, pack-years of cigarettes smoked, and occupational group in regression of models for $V C, F E V$, and $F E V, \mid V C \%$ in 668 men of the Zutphen study

\begin{tabular}{|c|c|c|c|c|c|c|}
\hline & \multicolumn{2}{|c|}{$V C(m l)$} & \multicolumn{2}{|c|}{$F E V_{1}(m l)$} & \multicolumn{2}{|c|}{$F E V, / V C \%$} \\
\hline & $\hat{\beta}$ & $S E$ & $\bar{\beta}$ & $S E$ & $\beta$ & $S E$ \\
\hline $\begin{array}{l}\text { Constant } \\
\text { Age }(y) \\
\text { Standing height }(\mathrm{cm}) \\
\text { Pack-years cigarettes } \\
\text { Blue collar workers } \dagger\end{array}$ & $\begin{array}{c}-3 \cdot 4 \\
-31 \cdot 8 \\
54 \cdot 7 \\
-5 \cdot 5 \\
24\end{array}$ & $\begin{array}{l}0 \cdot 8^{\star \star \star} \\
4 \cdot 6^{\star \star \star} \\
3 \cdot 9^{\star \star \star} \\
2 \cdot 1^{\star \star \star} \\
50\end{array}$ & $\begin{array}{r}-3.9 \\
-38.3 \\
32.5 \\
-7.5 \\
-159\end{array}$ & $\begin{array}{l}0 \cdot 7^{\star \star \star} \\
4 \cdot 4^{\star \star \star} \\
3 \cdot 7^{\star \star \star} \\
2 \cdot 0^{\star \star \star} \\
47^{\star \star \star}\end{array}$ & $\begin{array}{l}1.1 \\
-0.4 \\
-0.1 \\
-0.1 \\
-3.4\end{array}$ & $\begin{array}{l}0 \cdot 1^{\star \star \star} \\
0 \cdot 1^{\star \star \star} \\
0 \cdot 066^{\star} \\
0 \cdot 03^{\star \star} \\
0 \cdot 7^{\star \star \star}\end{array}$ \\
\hline Adjusted $\mathrm{r}^{2}(\%)$ & \multicolumn{2}{|c|}{31} & \multicolumn{2}{|c|}{24} & \multicolumn{2}{|c|}{9} \\
\hline
\end{tabular}

${ }^{\star} \mathrm{p}<0.05 ; \star \star \mathrm{p}<0.01 ;{ }^{\star \star \star} \mathrm{p}<0.001$.

$\beta=$ Regression coefficient; $\mathrm{SE}=$ standard error of $\hat{\beta}$.

†Compared with white collar workers. 
Table 3 Age, smoking habits, CNSLD mortality and total mortality of white and blue collar populations in Zutphen study in 1965

\begin{tabular}{|c|c|c|c|c|}
\hline \multirow[b]{3}{*}{$\begin{array}{l}\text { Age }(y) \\
\text { Pack-years cigarettes (pack/day.year) } \\
\text { No years smoked }\end{array}$} & \multicolumn{2}{|c|}{ White collar workers $(n=322)$} & \multicolumn{2}{|c|}{ Blue collar workers ( $n=346$ ) } \\
\hline & $\operatorname{Mean}(S D)$ & No $(\%)$ & Mean $(S D)$ & No $(\%)$ \\
\hline & $\begin{array}{l}54 \cdot 2(5 \cdot 4) \\
16 \cdot 3(12 \cdot 3) \\
29 \cdot 9(12 \cdot 3)\end{array}$ & & $\begin{array}{l}54.8(5 \cdot 4) \\
16.5(12 \cdot 2) \\
31 \cdot 4(12 \cdot 6)\end{array}$ & - \\
\hline $\begin{array}{l}\text { Non-cigarette smokers } \\
\text { Ex-cigarette smokers } \\
\text { Current cigarette smokers: }\end{array}$ & & $\begin{array}{rr}25(7.8) \\
121(37 \cdot 6)\end{array}$ & & $\begin{array}{lr}26 & (7.5) \\
93 & (26.9)\end{array}$ \\
\hline $\begin{array}{l}\text { <5 cigarettes per day } \\
5-9 \text { cigarettes per day } \\
10-19 \text { cigarettes per day } \\
20-29 \text { cigarettes per day } \\
\geqslant 30 \text { cigarettes per day } \\
\text { Current pipe or cigar smokers }\end{array}$ & & $\begin{array}{rr}19 & (5 \cdot 9) \\
30 & (9 \cdot 3) \\
70 & (21 \cdot 7) \\
48 & (14 \cdot 9) \\
9 & (2 \cdot 8) \\
204 & (63 \cdot 4)\end{array}$ & & $\begin{array}{rr}30 & (8 \cdot 7) \\
46 & (13 \cdot 3) \\
103(29 \cdot 8) \\
44(12 \cdot 7) \\
4(1 \cdot 2) \\
175(50 \cdot 6)\end{array}$ \\
\hline $\begin{array}{l}\text { Total mortality } \\
\text { CNSLD mortality } \\
\text { CNSLD incidence }\end{array}$ & & $\begin{aligned} 134 & (41 \cdot 6) \\
12 & (3 \cdot 7) \\
54 & (18 \cdot 3)(n=295)^{\star}\end{aligned}$ & & $\begin{array}{l}162(46 \cdot 8) \\
23(6 \cdot 6) \\
86(29 \cdot 5)(n=292)^{\star}\end{array}$ \\
\hline
\end{tabular}

*Total population size is smaller because those who developed CNSLD between 1960 and 1965 were excluded from the analysis.

CNSLD. For this particular analysis a group of 587 men remained.

Table 2 gives the results of the regression analyses of lung function variables on smoking, age, standing height, and occupation. Age, standing height, and pack-years contributed significantly to most of the regression models of $\mathrm{VC}, \mathrm{FEV}_{1}$, and $\mathrm{FEV}_{1} / \mathrm{VC} \%$. Blue collar workers had a significantly decreased $\mathrm{FEV}_{1}(-159 \mathrm{ml}, \mathrm{p}<0.05)$ and $\mathrm{FEV}_{1} / \mathrm{VC} \%$ $(-3.4 \%, \mathrm{p}<0.05)$ compared with white collar workers after allowing for smoking, whereas the VC did not differ significantly between the two groups. Because of the small size of subpopulations of blue collar workers, only a distinction between blue collar workers and white collar workers was made. Table 3 gives total mortality, and CNSLD incidence and mortality for both occupational categories. Of those who died from CNSLD only one died from asthma. Blue collar workers smoked somewhat longer than white collar workers, but this difference was not statistically significant ( $t$ test; $p>0.50$ ).

The proportional hazard analysis showed that

Table 4 Results of multivariate proportional hazard analysis for total mortality for 668 men in the Zutphen population

\begin{tabular}{|c|c|c|c|c|}
\hline & $\hat{\beta}$ & $S E$ & $H R$ & $(95 \% C I)$ \\
\hline $\begin{array}{l}\text { Model 1: } \\
\text { Age (y) } \\
\text { Pack-years (pack/day.years) } \\
\text { Blue } v \text { white collar workers }\end{array}$ & $\begin{array}{l}0.094 \\
0.011 \\
0.061\end{array}$ & $\begin{array}{l}0.011 \\
0.004 \\
0.12\end{array}$ & $\begin{array}{l}2.56^{\star} \\
1.12 \dagger \\
1.06\end{array}$ & $\begin{array}{l}(2 \cdot 06-3 \cdot 18) \\
(1.02-1 \cdot 22) \\
(0 \cdot 84-1 \cdot 34)\end{array}$ \\
\hline $\begin{array}{l}\text { Model 2: } \\
\text { Age (y) } \\
\text { Pack-years (pack/day.years) } \\
\text { Blue } v \text { white collar workers } \\
\text { VC }_{\text {residual }}(0 \text { to }-640 \mathrm{ml}) \\
\mathrm{VC}_{\text {residual }}(-640 \text { to }-1280 \mathrm{ml}) \\
\text { VC }_{\text {residuel }}(<-1280 \mathrm{ml})\end{array}$ & $\begin{array}{l}0.092 \\
0.010 \\
0.061 \\
0.01 \\
0.35 \\
0.55\end{array}$ & $\begin{array}{l}0.011 \\
0.004 \\
0 \cdot 12 \\
0 \cdot 13 \\
0 \cdot 18 \\
0 \cdot 26\end{array}$ & $\begin{array}{l}2 \cdot 51 \star \\
1 \cdot 11 \dagger \\
1.06 \\
1.01 \\
1 \cdot 42 \\
1.73\end{array}$ & $\begin{array}{l}(2 \cdot 02-3 \cdot 11) \\
(1 \cdot 02-1 \cdot 20) \\
(0 \cdot 84-1 \cdot 34) \\
(0 \cdot 78-1 \cdot 30) \\
(0 \cdot 99-2 \cdot 02) \\
(1 \cdot 04-2 \cdot 89)\end{array}$ \\
\hline $\begin{array}{l}\text { Model 3: } \\
\text { Age (y) } \\
\text { Pack-years (pack/day.years) } \\
\text { Blue } v \text { white collar workers } \text { FEV }_{1} \text { residual }(0 \text { to }-620 \mathrm{ml}) \\
\mathrm{FEV}_{1} \text { residual }(-620 \text { to }-1240 \mathrm{ml}) \\
\text { FEV }_{1} \text { residual } \\
(<-1240 \mathrm{ml})\end{array}$ & $\begin{array}{l}0.095 \\
0.008 \\
0.033 \\
0.28 \\
0.45 \\
1.05\end{array}$ & $\begin{array}{l}0.011 \\
0 \cdot 005 \\
0 \cdot 12 \\
0 \cdot 13 \\
0 \cdot 20 \\
0 \cdot 23\end{array}$ & $\begin{array}{l}2 \cdot 59 \star \\
1.08 \dagger \\
1.03 \\
1.32 \\
1.57 \\
2 \cdot 86\end{array}$ & $\begin{array}{l}(2 \cdot 08-3 \cdot 21) \\
(0.99-1 \cdot 17) \\
(0 \cdot 82-1.31) \\
(1.03-1.71) \\
(1.06-2.32) \\
(1.82-4.49)\end{array}$ \\
\hline 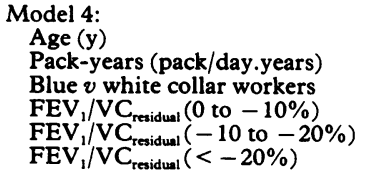 & $\begin{array}{l}0.094 \\
0.010 \\
0.002 \\
0 \cdot 22 \\
0 \cdot 40 \\
0.81\end{array}$ & $\begin{array}{l}0 \cdot 011 \\
0 \cdot 003 \\
0 \cdot 12 \\
0 \cdot 14 \\
0 \cdot 19 \\
0 \cdot 23\end{array}$ & $\begin{array}{l}2 \cdot 56^{\star} \\
1 \cdot 11 \dagger \\
1.00 \\
1 \cdot 25 \\
1.50 \\
2 \cdot 25\end{array}$ & $\begin{array}{l}(2 \cdot 06-3 \cdot 18) \\
(1 \cdot 04-1 \cdot 17) \\
(0 \cdot 79-1 \cdot 27) \\
(0.95-1 \cdot 64) \\
(1 \cdot 03-2 \cdot 16) \\
(1 \cdot 43-3 \cdot 53)\end{array}$ \\
\hline
\end{tabular}

$\hat{\beta}=$ Regression coefficient; $\mathrm{SE}=$ standard error of $\hat{\beta} ; \mathrm{HR}=$ hazard ratio.

*Hazard ratio expressed per 10 years.

+Hazard ratio expressed per 10 pack-years. 
Table 5 Results of multivariate proportional hazard analysis for CNSLD mortality for 668 men in the Zutphen population

\begin{tabular}{|c|c|c|c|c|}
\hline & $\hat{\beta}$ & $S E$ & $H R$ & $(95 \% C I)$ \\
\hline $\begin{array}{l}\text { Model 1: } \\
\text { Age (y) } \\
\text { No years smoked (y) } \\
\text { Blue } v \text { white collar workers }\end{array}$ & $\begin{array}{l}0.056 \\
0.067 \\
0.34\end{array}$ & $\begin{array}{l}0.043 \\
0.029 \\
0.37\end{array}$ & $\begin{array}{l}1.75^{\star} \\
1.95^{\star} \\
1.40\end{array}$ & $\begin{array}{l}(0.75-4.07) \\
(1.11-3.45) \\
(0.68-2.90)\end{array}$ \\
\hline $\begin{array}{l}\text { Model 2: } \\
\text { Age (y) } \\
\text { No years smoked (y) } \\
\text { Blue } v \text { white collar workers } \\
\text { VC } \\
\text { VCeridual }(0 \text { to }-640 \mathrm{ml}) \\
\text { VC }_{\text {residual }}(-640 \text { to }-1280 \mathrm{ml}) \\
(<-1280 \mathrm{ml})\end{array}$ & $\begin{array}{l}0 \cdot 039 \\
0 \cdot 069 \\
0 \cdot 39 \\
0 \cdot 81 \\
1 \cdot 29 \\
2 \cdot 50\end{array}$ & $\begin{array}{l}0.044 \\
0.031 \\
0.37 \\
0.44 \\
0.52 \\
0.55\end{array}$ & $\begin{aligned} 1 \cdot 48^{\star} \\
1.99^{\star} \\
1 \cdot 48 \\
2 \cdot 25 \\
3 \cdot 63 \\
12 \cdot 18\end{aligned}$ & $\begin{array}{l}(0.62-3.50) \\
(1.09-3.66) \\
(0.72-3.05) \\
(0.95-5 \cdot 32) \\
(1.31-10.07) \\
(4.15-35.80)\end{array}$ \\
\hline $\begin{array}{l}\text { Model 3: } \\
\text { Age (y) } \\
\text { No years smoked (y) } \\
\text { Blue } v \text { white collar workers } \\
\text { FEV } \\
\text { FEV readual }(0 \text { to }-620 \mathrm{ml}) \\
\text { FEV }_{1 \text { residual }}(<-620 \text { to }-1240 \mathrm{ml}) \\
(<-1240 \mathrm{ml})\end{array}$ & $\begin{array}{l}0 \cdot 060 \\
0 \cdot 068 \\
0 \cdot 31 \\
1 \cdot 21 \\
2 \cdot 43 \\
3 \cdot 24\end{array}$ & $\begin{array}{l}0.043 \\
0.032 \\
0.36 \\
0.51 \\
0.52 \\
0.55\end{array}$ & $\begin{array}{l}1.82^{\star} \\
1.97^{\star} \\
1.36 \\
3.35 \\
11.35 \\
25.53\end{array}$ & $\begin{array}{l}(0 \cdot 78-4 \cdot 23) \\
(1 \cdot 05-3 \cdot 70) \\
(0 \cdot 67-2 \cdot 76) \\
(1 \cdot 23-9 \cdot 11) \\
(4 \cdot 10-31 \cdot 48) \\
(8 \cdot 69-75 \cdot 04)\end{array}$ \\
\hline 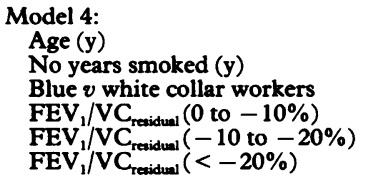 & $\begin{array}{l}0.057 \\
0.065 \\
0 \cdot 14 \\
0.45 \\
2 \cdot 00 \\
2 \cdot 48\end{array}$ & $\begin{array}{l}0.043 \\
0.031 \\
0.37 \\
0.51 \\
0.45 \\
0.49\end{array}$ & $\begin{array}{r}1 \cdot 77^{\star} \\
1.92^{\star} \\
1 \cdot 15 \\
1.57 \\
7.38 \\
11.94\end{array}$ & $\begin{array}{l}(0 \cdot 76-4 \cdot 11) \\
(1 \cdot 04-3 \cdot 52) \\
(0.56-2 \cdot 38) \\
(0.58-4 \cdot 26) \\
(3.06-17 \cdot 85) \\
(4 \cdot 57-31 \cdot 20)\end{array}$ \\
\hline
\end{tabular}

For explanations see footnote to table 4.

pack-years of cigarettes smoked was a better predictor of total mortality than the number of years smoked up to 1965. Cigar and pipe smoking did not contribute to any of the models for total mortality ( $p>0.80$ ). These variables were therefore omitted in further models. Age in 1965 was highly significantly related to total mortality. All further models tested, therefore, contained the variables.age and pack-years of cigarettes smoked. Table 4 presents the results of the proportional hazards model for total mortality with different combinations of variables. Age and pack-years of cigarettes were always included as confounders. Those persons who had a blue collar job in 1965 showed a slightly increased total mortality, but the difference when compared with white collar workers was not statistically significant. The addition of three dummy variables for four categories of lung function residues showed that the non-significant effect of a blue collar job diminishes further (models 2, 3, and 4 compared to model 1). As can be seen, a reduced lung function is a strong predictor of total mortality.

Blue collar workers had a higher mortality from CNSLD than white collar workers after correcting for age and duration of smoking up to 1965 (table 5). The hazard ratio for blue collar workers compared with white collar workers (1.40, model 1$)$, however, was not statistically significant. This hazard ratio decreased after dummy variables for the $\mathrm{FEV}_{1} / \mathrm{VC} \%$ residuals were entered into the model. The survival curve for white and blue collar workers (fig 1) shows that the excess mortality among blue collar workers appeared only after more than 10 years of follow up. Omission of these first 10 years resulted in an increase of the hazard ratio for blue compared with white collar workers although it did not reach statistical significance ( $n=576$, hazard ratio $1 \cdot 72$, $\mathrm{p}=0 \cdot 20$ ). An analysis in which subgroups of blue collar workers were studied did not show any statistically significant differences in CNSLD or total mortality compared with white collar workers. Again the $\mathrm{FEV}_{1}$ seemed to be the strongest predictor of CNSLD mortality compared with the VC and $\mathrm{FEV}_{1} / \mathrm{VC} \%$. Figure 2 shows the survival curves for the significant correlation between CNSLD mortality and FEV, level in 1965. Duration of smoking up to 1965 appeared to be a superior predictor of mortality than the number of pack-years of cigarettes smoked or cigarette consumption in 1965. This last variable was further studied in a stratified analysis within the proportional hazard model as explained in the methods section, but the results were poor compared with analyses of the duration of cigarette smoking as the explanatory variable in the model. An analysis with both duration of smoking and number of cigarettes smoked did not improve the model. Age and number of years smoked therefore were used as confounders in all other models for CNSLD mortality. Numbers of pack-years did not alter the proportional hazards assumption for incidence of CNSLD as it did for CNSLD mortality. This variable was used, therefore, in the multivariate 


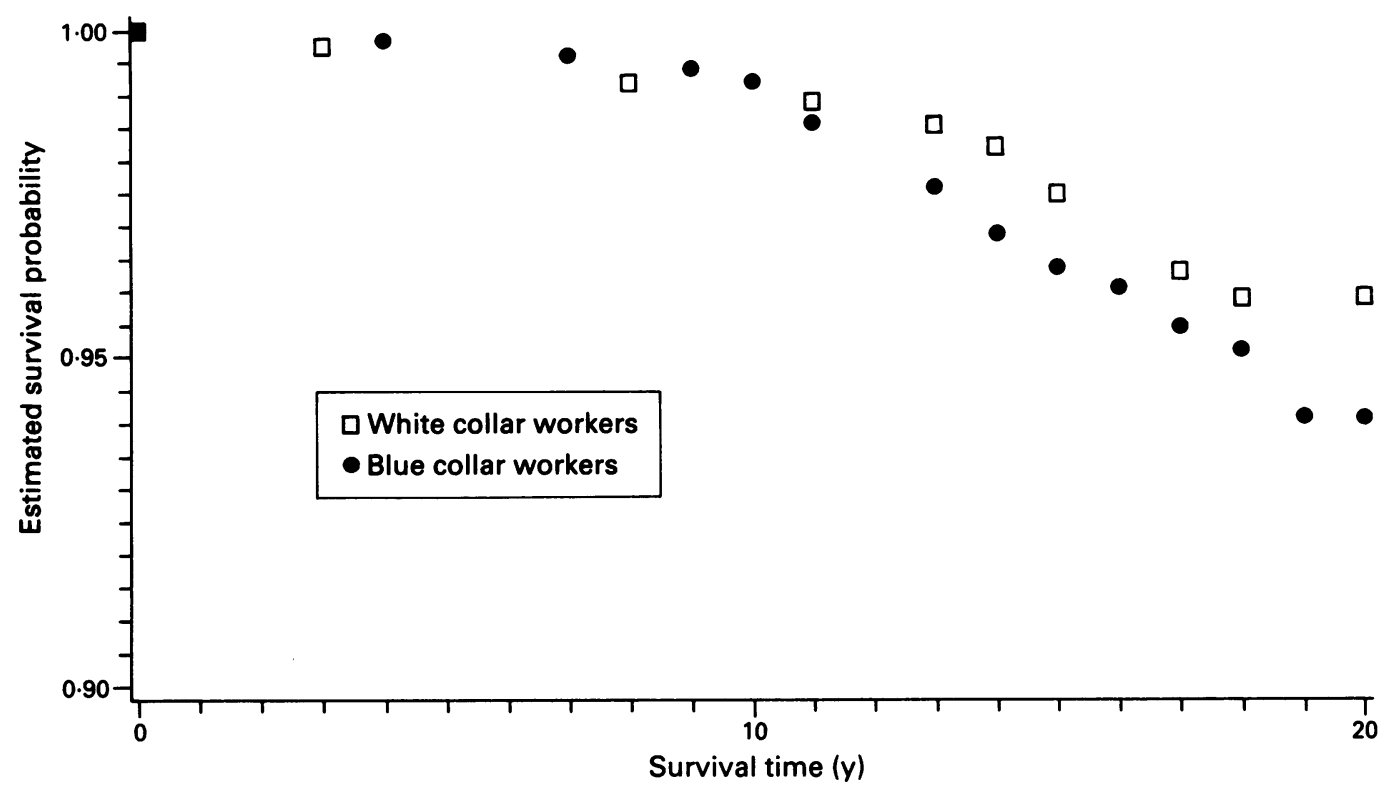

Figure 1 Survival curves for CNSLD mortality for blue and white collar workers in the Zutphen Study population corrected for age and smoking.

proportional hazard analysis. The proportional hazard analysis showed that incidence of CNSLD was greater among blue collar workers than white collar workers, after correcting for age and packyears (table 6 , fig 3 ). The magnitude of the hazard ratio for blue $v$ white collar workers remained statistically significant after inclusion of the lung function residuals in the model (models 2,3 , and 4 compared with model 1). FEV 1 residuals were the strongest predictor of incidence of CNSLD com-

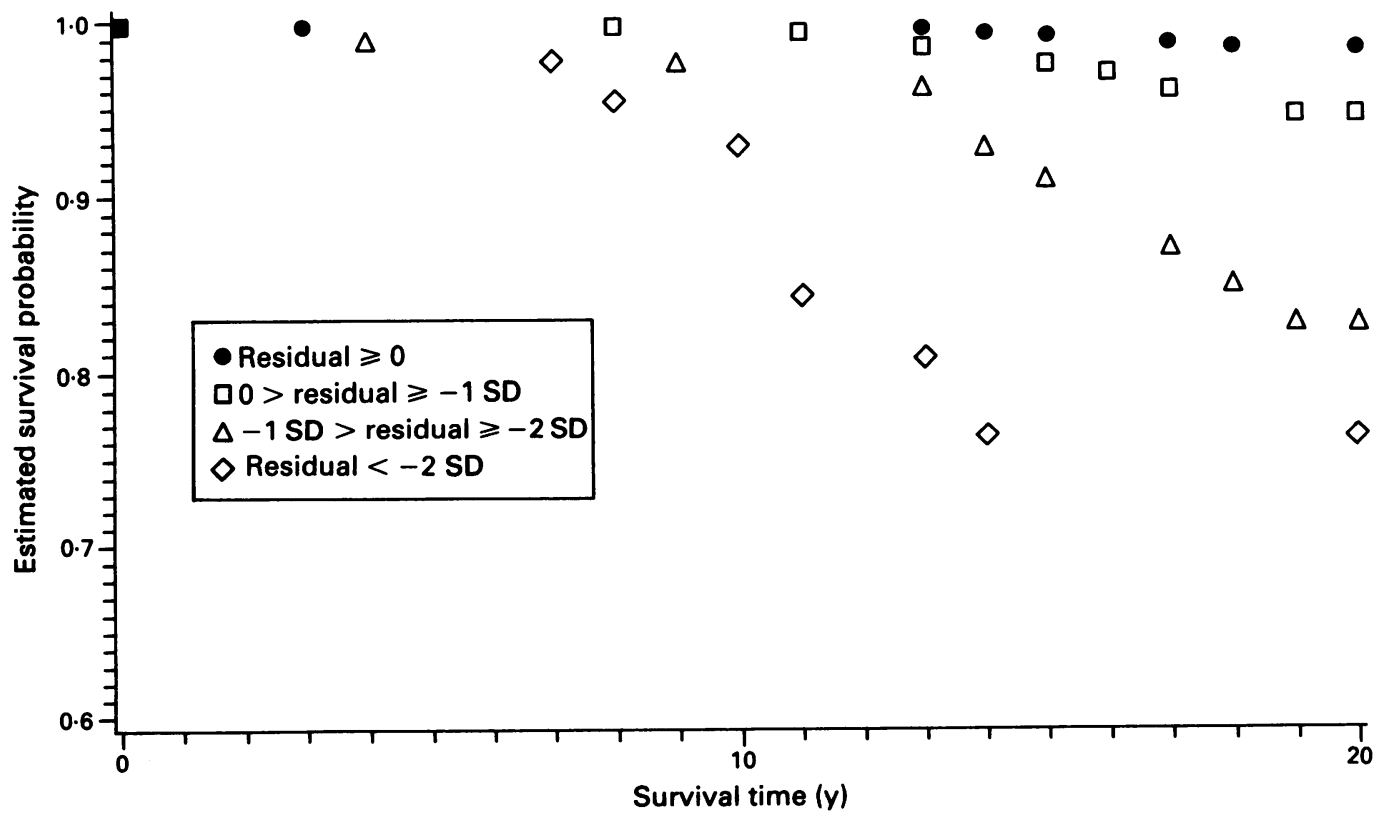

Figure 2 Survival curves for CNSLD mortality by FEV, residual category in the Zutphen Study population corrected for age, occupation (0/1), and smoking. 
Table 6 Results of multivariate proportional hazard analysis for incidence of CNSLD in 587 men in the Zutphen population

\begin{tabular}{|c|c|c|c|c|}
\hline CNSLD incidence & $\hat{\beta}$ & $S E$ & $H R$ & $(95 \% C I)$ \\
\hline $\begin{array}{l}\text { Model 1: } \\
\text { Age (y) } \\
\text { Pack-years (pack/day.years) } \\
\text { Blue } v \text { white collar workers }\end{array}$ & $\begin{array}{l}0.037 \\
0.025 \\
0.52\end{array}$ & $\begin{array}{l}0.016 \\
0.001 \\
0.18\end{array}$ & $\begin{array}{l}1.45^{\star} \\
1.28 \dagger \\
1.68\end{array}$ & $\begin{array}{l}(1.06-1.98) \\
(1.26-1.31) \\
(1.18-2.39)\end{array}$ \\
\hline $\begin{array}{l}\text { Model 2: } \\
\text { Age (y) } \\
\text { Pack-years (pack/day.years) } \\
\text { Blue } v \text { white collar workers } \\
\text { VC }_{\text {reaidual }}(0 \text { to }-640 \mathrm{ml}) \\
\text { VC }_{\text {retidual }}(-640 \text { to }-1280 \mathrm{ml}) \\
\text { VC }_{\text {reaidual }}(<-1280 \mathrm{ml})\end{array}$ & $\begin{array}{l}0.031 \\
0.024 \\
0.54 \\
0.23 \\
0.93 \\
0.95\end{array}$ & $\begin{array}{l}0.016 \\
0 \cdot 001 \\
0 \cdot 18 \\
0 \cdot 19 \\
0 \cdot 24 \\
0 \cdot 47\end{array}$ & $\begin{array}{l}1 \cdot 36^{\star} \\
1 \cdot 27 \dagger \\
1 \cdot 71 \\
1 \cdot 26 \\
2 \cdot 53 \\
2 \cdot 59\end{array}$ & $\begin{array}{l}(1.00-1.87) \\
(1.25-1.30) \\
(1.21-2.44) \\
(0.87-1.83) \\
(1.58-4.06) \\
(1.03-6.50)\end{array}$ \\
\hline $\begin{array}{l}\text { Model 3: } \\
\text { Age (y) } \\
\text { Pack-years (pack/day.years) } \\
\text { Blue } v \text { white collar workers } \text { FEV } \\
\text { FEV redual }(0 \text { to }-620 \mathrm{ml}) \\
\text { FEV }_{1 \text { redidual }}(-620 \text { to }-1240 \mathrm{ml}) \\
(<-1240 \mathrm{ml})\end{array}$ & $\begin{array}{l}0.036 \\
0.023 \\
0.55 \\
0.61 \\
1.54 \\
2.55\end{array}$ & $\begin{array}{l}0.015 \\
0.001 \\
0.18 \\
0.19 \\
0.24 \\
0.39\end{array}$ & $\begin{array}{l}1.43^{\star} \\
1.26 \dagger \\
1.73 \\
1.84 \\
4.66 \\
12.81\end{array}$ & $\begin{array}{l}(1.07-1.92) \\
(1.24-1 \cdot 28) \\
(1.22-2 \cdot 47) \\
(1.27-2 \cdot 67) \\
(2.91-7.47) \\
(5.96-27.51)\end{array}$ \\
\hline 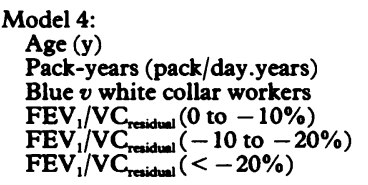 & $\begin{array}{l}0.042 \\
0.025 \\
0.42 \\
0.51 \\
1.59 \\
1.93\end{array}$ & $\begin{array}{l}0.016 \\
0.001 \\
0 \cdot 18 \\
0 \cdot 19 \\
0 \cdot 23 \\
0.52\end{array}$ & $\begin{array}{l}1.52 \star \\
1.28 \dagger \\
1.58 \\
1.67 \\
4.90 \\
6.89\end{array}$ & $\begin{array}{l}(1 \cdot 11-2 \cdot 08) \\
(1 \cdot 26-1 \cdot 31) \\
(1 \cdot 07-2 \cdot 17) \\
(1 \cdot 15-2 \cdot 42) \\
(3 \cdot 12-7 \cdot 70) \\
(2 \cdot 49-19 \cdot 10)\end{array}$ \\
\hline
\end{tabular}

For explanations see footnote to table 4.

pared with $\mathrm{FEV}_{1} / \mathrm{VC} \%$ and VC residuals. Figure 4 gives the survival curves for four $\mathrm{FEV}_{1}$ residual categories.

\section{Discussion}

All blue collar occupational groups combined had a lower lung function than white collar workers after allowing for age, standing height, and pack-years smoked. The lower levels of lung function were seen for $\mathrm{FEV}_{1}$ and $\mathrm{FEV}_{1} / \mathrm{VC} \%$ but not for VC, suggesting obstructive changes. Although no specific exposures were ever registered or monitored for these subgroups, previous analysis in this study with the use of a so called job exposure matrix showed that all the blue collar subgroups had occupational exposures to dusts, and some to gases and fumes. ${ }^{20} 23$ The previous analysis of cross sectional data showed that some of these exposures were related to respiratory symptoms. ${ }^{23}$ The longitudinal analysis showed that those with an occupational exposure to dust, gases, or fumes had a statistically significant increased incidence density of CNSLD (incidence density ratio 1.40 (95\% confidence interval (95\% CI) 1.07-1.85)) after allowing for age, calendar period, and smoking habits in a multivariate Poisson regression. ${ }^{20}$

The decreases in lung function among blue collar workers were in a $1-5 \%$ range in this study, generally not considered to be disabling reductions.

Total mortality did not differ significantly between white and blue collar workers. Mortality from CNSLD between blue and white collar workers differed with borderline significance. The proportional hazard analysis for mortality from CNSLD resulted in a non-significant regression coefficient for blue compared with white collar workers after correction for smoking habits and age (hazard ratio $=1 \cdot 4)$. Age was, as expected, significantly related to mortality in almost all models. Smoking habits were positively related to both total mortality and mortality from CNSLD, although for mortality from CNSLD the relation was not as straightforward as might be expected. The analysis with the number of cigarettes consumed per day showed that at some point during follow up, survival curves of the white and blue collar groups crossed. This might reflect the effect.of changing smoking habits resulting in a sort of "healthy smoker" effect. The number of years smoked did not show such an effect and was therefore used for further analysis. The hazard ratio of duration of smoking and mortality from CNSLD was large. For every 10 years of smoking the hazard ratio was 1.95, resulting in a hazard ratio of 7.5 after 30 years of smoking cigarettes, roughly the mean duration of smoking in this population. After inclusion of $\mathrm{FEV}_{1 \text { residuals }}$ in the proportional hazard model, smoking remained a statistically significant predictor of subsequent total mortality, mortality from CNSLD and incidence of CNSLD. This probably reflects the ongoing effect of smoking on health after 1965, because exposure to tobacco smoke continued. 


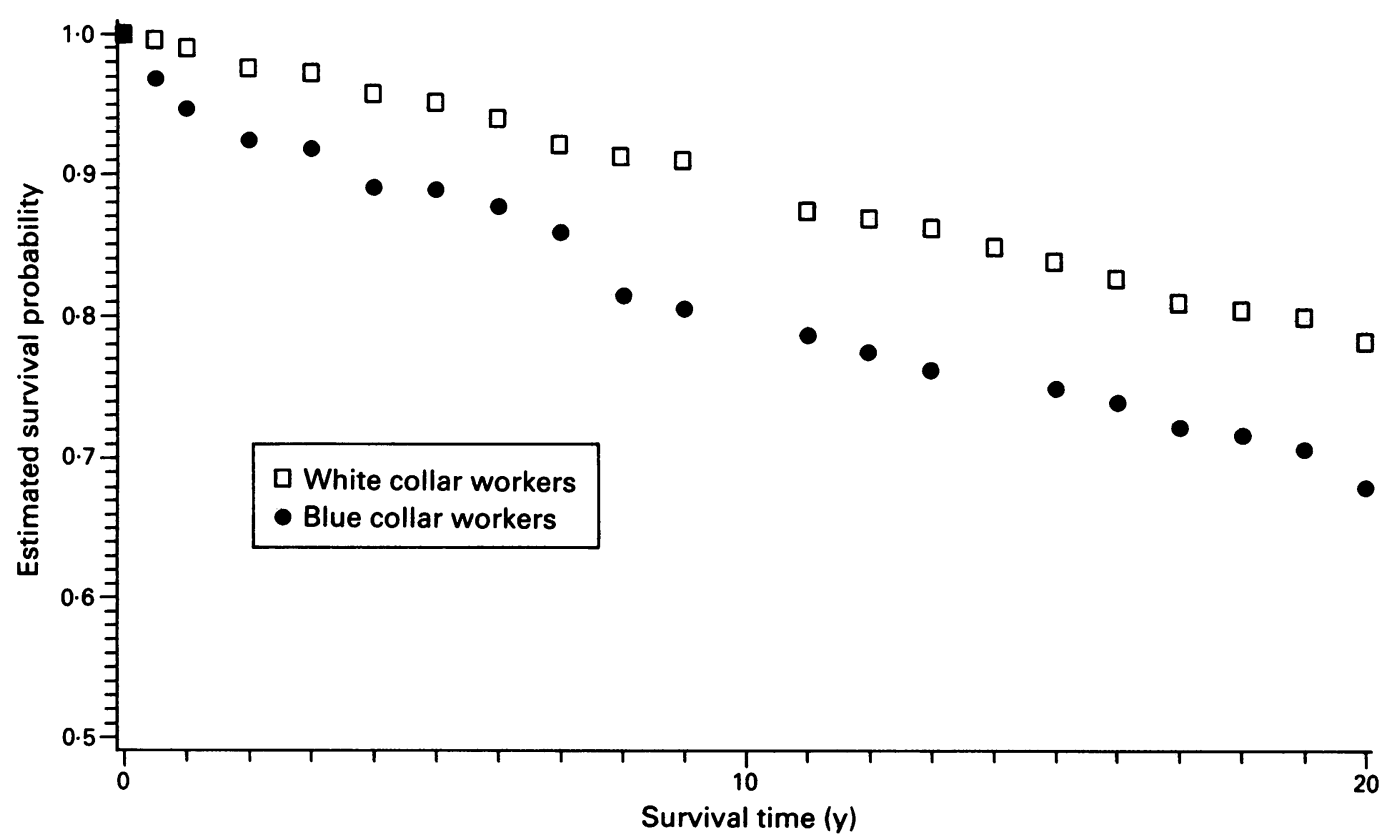

Figure 3 Survival curves for CNSLD incidence for blue and white collar workers in the Zutphen Study population corrected for age and smoking.

It is recognised that the accuracy of the death certificate in reporting cause of death is in some countries considered low, especially for CNSLD, leading to an underestimation of the contribution of these diseases to total mortality. In a recent study in the European Community, however, it was found that a sample of physicians had a detection rate from 60 to $92 \%$ for CNSLD (The Netherlands: $91 \%$ ) if they were asked to certify a set of case histories that were further coded by the national coding offices. ${ }^{24}$

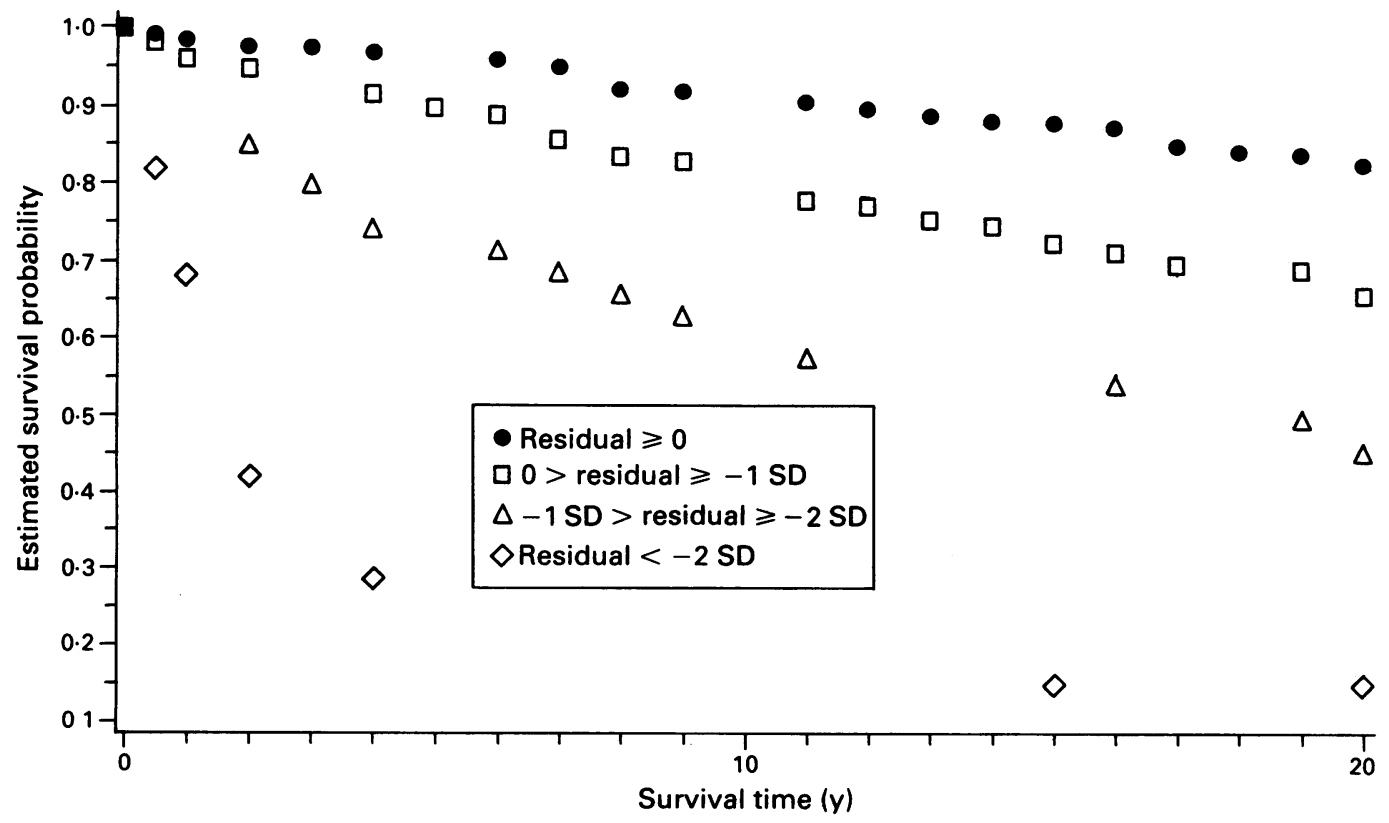

Figure 4 Survival curves for incidence of CNSLD by FEV, residual category in the Zutphen Study population corrected for age, occupation (0/1), and smoking. 
Despite the reasonable accuracy of Dutch death certificates, information bias might have influenced the findings of this study. Generally an internal comparison within the same study population, as conducted in the present analysis, is regarded as the best approach possible to avoid such biases.

A lowered lung function, especially a lowered $\mathrm{FEV}_{1}$ was a very strong predictor of total mortality and especially of mortality from CNSLD. For those with residual $\mathrm{FEV}_{1}$ less than two SDs of the mean $\mathrm{FEV}_{1}$ a hazard ratio of 25 was reached with mortality from CNSLD. Persons with a less severely lowered lung function also showed a significantly raised risk for total mortality and mortality from CNSLD. The relation between a lowered FEV $_{1}$ and CNSLD mortality has been reported previously, although a detailed comparison cannot be made because of differences in the calculations. ${ }^{9}$ Several explanations have been suggested for a relation between lung function, especially $F E V_{1}$ reductions, and total mortality or non-respiratory causes of death. ${ }^{246}$ These relations might reflect a lower lung function, which occurs as a result of other disease processes. Risk factors that produce a lowered lung function might also be risk factors for other, non-respiratory, causes of death. A third explanation might be that normal lung function is a prerequisite for wellbeing of the whole organism. In our analysis we found that if cases with CNSLD as a cause of death were excluded from the analysis, the relations between total mortality, smoking, lung function, and age diminished but remained statistically significant. This suggests that a lowered lung function is related to other causes of death, such as cardiovascular diseases, as well as to CNSLD. Inferences about causal pathways linking low lung function, smoking, and occupation are difficult because the results of the Zutphen Study are strongly biased towards the mortality of a smoking population. More than $90 \%$ of this population had ever smoked cigarettes and a major proportion was still smoking cigarettes during the follow up period. The subgroup of non-smokers was too small to derive any definite conclusions about the effect of a lowered lung function and an occupational exposure on CNSLD incidence and mortality for this subpopulation. In other studies generally no distinction has been made in the analysis between smokers and non-smokers. In the study of Vollmer et al ${ }^{12}$ a distinction between smokers and non-smokers was made. They found that different factors were related to mortality from all causes within different smoking categories. The absolute number of deaths in the non-smoking category, however, was low and to give definite answers was, therefore, not possible.

Although no specific exposures were studied, no increased total mortality was found for those workers who were likely to have had an exposure to dusts, fumes, or gases in their job. This finding is by contrast with findings from another study in France. ${ }^{6}$ The crude characterisation of occupational exposure in the French study might be one explanation for this discrepancy and qualitative differences in occupational exposure might be another. The relative contribution of mortality from CNSLD to total mortality is small. A rise in mortality from CNSLD will probably not lead to an appreciable rise in total mortality. The relation between dust exposure and total mortality found in the French study can therefore only be explained by an increase of one or several specific causes of death with a large relative contribution to total mortality. More detailed information on the composition of that cohort and its mortality is necessary to explain the differences.

Although the size of the hazard ratio for CNSLD mortality for blue $v$ white collar workers seemed to make this relevant, it was statistically non-significant, probably because the small number of deaths from CNSLD resulted in limited statistical power. The size of the effect of an occupation on CNSLD mortality encountered in the present study was small compared with the effect of smoking. If the effect of a lower lung function on mortality from CNSLD is considered, the hazard ratio of occupation on CNSLD mortality is of the same order of magnitude as the hazard ratio for persons with a slightly lowered lung function.

The survival analysis using incidence of CNSLD showed a statistically significant relation between occupation, blue $v$ white collar workers, and CNSLD morbidity after correction for age and smoking. The relation between occupational exposure and incidence of CNSLD remained statistically significant after inclusion of the four categories for lung function residuals in the model. This suggests an ongoing effect of occupation after the start of follow up in 1965, independent of degree of lung function in 1965. These results do not necessarily reflect the ongoing effects of occupational exposures. We realise that the Zutphen study population consists of men who were born at the beginning of the century so cohort effects may be present. Such effects might be caused by severe airway infections during the first part of the century as a result of poor housing conditions, crowding, and malnutrition, and because adequate treatment was absent in those days. Others have pointed to the potential importance of childhood respiratory illness in the development of adult chronic lung disease, ${ }^{25-27}$ although no definite conclusions can be made yet.

By contrast, however, our previous analyses of the Zutphen cohort showed relations between specific exposures and CNSLD symptoms and CNSLD incidence, which indicated a significant contribution of occupational exposures to the development of CNSLD. 
In conclusion, smoking habits and a lower lung function are strong predictors of total mortality and mortality from CNSLD, whereas occupation appears to be weakly associated with mortality from CNSLD, but clearly with incidence of CNSLD. To derive more precise estimates of the contribution of occupational exposure to mortality from CNSLD and total mortality, studies have to be undertaken in which occupational exposure is characterised in greater detail.

We thank Bennie Bloemberg, MSc for data retrieval, Jos van Hutten for her assistance with coding of the occupation of the participants, Marjon Drijver MD for coding the incidence data, Bert Brunekreef, $\mathrm{PhD}$ for his critical and useful comments on earlier versions of the manuscript, Ms LM Friden-Kill, MD Central Bureau of Statistics for her assistance with coding the causes of death, and Ms BDA Kluver (NIPG-TNO) for the lung function measurements. Last but not least we thank the participants for their long term cooperation in the study. This study was funded by The Netherlands Prevention Foundation.

Requests for reprints to: Dr Dick Heederik, Department of Epidemiology and Public Health, Wageningen University, PO box 238, $6700 \mathrm{AE}$ Wageningen, The Netherlands.

1 Higgins MW, Keller JB. Predictors of lung function in the adult population of Tecumseh. Arch Environ -Health 1970;21: 418-24.

2 Kannel WB, Seidman JM, Fercho MS. Vital capacity and congestive heart failure: the Framingham study. Circulation $1974 ; 49: 1160-6$.

3 Todd GF, Hunt BM, Lambert PM. Four cardio respiratory symptoms as predictors of mortality. J Epidemiol Community Health 1978;32:267-74.

4 Beaty TH, Newill CA, Cohen BH. Effects of pulmonary function on mortality. J Chron Dis 1985;38:703-10.

5 Peto R, Speizer FE, Cochrane AL, Moore F, Fletcher CM, Tinker CM, et al. The relevance of air-flow obstruction, but not of mucus hypersecretion, to mortality from chronic lung disease. Am Rev Respir Dis 1983;128:491-500.

6 Annesi I, Kauffmann F. Is respiratory mucus hypersecretion really an innocent disorder. Am Rev Respir Dir 1986;134: 688-93.

7 Krzyzanowski $M$, Wysocki $M$. The relation of thirteen-year mortality to ventilatory impairment and other respiratory symptoms: the Cracow study. Int J Epidemiol 1986;15:56-64.
8 Carpenter L, Beral V, Strachan D, Ebi-Kryston L, Inskip H. Respiratory symptoms as predictors of 27 year mortality in a representative sample of British adults. BMJ 1989;299: 357-61.

9 Ebi-Kryston KL. Predicting 15 year chronic bronchitis mortality in the Whitehall Study. $J$ Epidemiol Community Health 1989;43:168-72.

10 Ebi-Kryston KL, Hawthorne VM, Rose G, Shipley MJ, Gillis GR, Hole DJ, et al. Breathlessness, chronic bronchitis, and reduced pulmonary function as predictors of cardiovascular disease mortality among men in England, Scotland and the United States. Int J Epidemiol 1989;18:84-8.

11 Sorlie PD, Kannel WB, O'Connor G. Mortality associated with respiratory function and symptoms in advanced age. The Framingham study. Am Rev Respir Dis 1989;140:379-84.

12 Vollmer WM, McCamant LE, Johnson LR, Buist AS. Respiratory symptoms, lung function and mortality in a screening center cohort. Am J Epidemiol 1989;129:1157-65.

13 Morgan WKC. On dust, disability and death. Am Rev Respir Dis 1986;134:639-41.

14 Kauffmann F, Annesi I. On dust disability and death. Letter to the editor. Am Rev Respir Dis 1987;134:1216-7.

15 Bates DV. On dust disability and death. Letter to the editor. Am Rev Respir Dis 1987;134:1215.

16 Franzblau A. The effect of occupation and smoking on respiratory disease mortality. Letter to the editor. Am Rev Respir Dis 1987;134:1219-30.

17 Keys A, Aravanis C, Blackburn H, et al. Epidemiological studies related to coronary heart disease: characteristics of men aged 40-59 in seven countries. Acta Med Scand 1967;Suppl:460.

18 Central Statistical Office. Standard industrial classification. London: HMSO, 1968.

19 General Register Office. Standard industrial classification. London: HMSO, 1968.

20 Heederik D, Kromhout H, Burema J, Biersteker K, Kromhout D. Occupational exposure and 25-year incidence rate of nonspecific lung disease-the Zutphen study. Int J Epidemiol 1990;19:945-52.

21 Timmers J. Cardiorespiratory findings in a male working population. Groningen: Wolters-Noordhof, 1969. (In Dutch, English summary.) (Thesis.)

22 Cox DR. Regression models and life tables (with discussion). Journal of the Royal Statistical Society 1972;B34:187-220.

23 Heederik D, Pouwels H, Kromhout H, Kromhout D. Chronic non-specific lung disease and occupational exposures estimated by means of a job exposure matrix-the Zutphen study. Int J Epidemiol 1989;18:382-9.

24 Mackenbach JP, van Duyne WMJ, Kelson M. Certification and coding of two underlying causes of death in the Netherlands and other countries of the European Community. Int J Epidemiol 1987;41:156-60.

25 Samet JM, Tager IB, Speizer FE. The relationship between respiratory illness in childhood and chronic air-flow obstruction in adulthood. Am Rev Respir Dis 1983;127:508-23.

26 Burr ML, Holliday RM. Why is chest disease so common in South Wales? Smoking, social class, and lung function: a survey of elderly men in two areas. J Epidemiol Community Health 1987;41:140-4.

27 Barker DJP, C Osmond. Childhood respiratory infection and adult chronic bronchitis in England and Wales. BMJ 1986; 239:1271-5.

Accepted 2 September 1991 